\title{
A Crosscultural Study on the Correlation Between Achievement Levels and Motivational Types of Values of Language Learners
}

\author{
Feryal Cubukcu
}

Dokuz Eylul University, Turkey

\begin{abstract}
Received 6 August $2017 \quad$ Accepted 15 October 2017

Most social scientists view values as deeply rooted, abstract motivations that guide, justify or explain attitudes, norms, opinions and actions. Values are basic orientations presumed to underlie and influence individual variation on many of the constructs that researchers from different disciplines wish to study. Since 1950s the main features of the conception of basic values implicit in the related literature are: 1 . Values are beliefs, cognitive structures that are closely linked to affect. 2 . Values refer to desirable goals. For example, social equality, fairness and helpfulness are all values. 3. Values transcend specific actions and situations. Obedience and honesty, for example, are values that may be relevant at work or in school, in sports, business and politics, with family, friends or strangers. 4. Values serve as standards or criteria. 5. Values are ordered by importance relative to one another. Cultures and individuals can be characterized by their systems of value priorities. Among all the scales, The Schwartz Value Survey (SVS) (1992) is currently the most widely used by social and cross-cultural psychologists for studying the individual differences in values. Schwartz derived ten, motivationally distinct, broad and basic values from three universal requirements of the human condition: needs of individuals as biological organisms, requisites of coordinated social interaction, and survival and welfare needs of groups. The ten basic values are intended to include all the core values recognized in cultures around the world (power, achievement, hedonism, stimulation, self-direction, universalism, benevolence, tradition, conformity, security). To primarily showcase whether there is a correlation between the success levels of the language learners and their motivational type of values, and secondly to explore whether this is culture specific or not, 56 language learners participated in the study and The Schwartz Values Questionnaire was administered. The study is expected to yield insight into the pursuit of the correlation between the proficiency levels of the language learners and their motivational types of values.
\end{abstract}

Keywords: Motivational Values, Achievement, Language Learning 


\section{Introduction}

The past decades have elaborated a large body of second language research targeting language learning strategies (Chamot et al. 1999; Cohen 1998, 2002; O’Malley et al. 1985; O'Malley and Chamot 1990; Oxford 1990, 1996). While some of these studies have explicitly sought to push the theoretical understanding of language learning strategies forward, there are a lot of research in the field of learning strategy literature to find out ways of empowering language learners to become more self-directed and effective in their learning.

This article presents an overview of the Schwartz theory of basic human values. It discusses the nature of values and spells out the features that are common to all values and what distinguishes one value from another. The theory highlights ten basic personal values that are identified across cultures and explains their pecularities. At the heart of the theory is the idea that values form a circular structure that reflects the motivations and each value stands for soem particular motivation types. This circular structure which captures the conflicts and compatibility among the ten values is apparently culturally universal.

Values have been a central concept in the social sciences since their inception and have played an important role not only in sociology, but in psychology, anthropology, and related disciplines as well. For both Durkheim (1897/1964) and Weber (1905/1958), values were highly significant for explaining social and personal organization and change. Values are used to characterize cultural groups, societies, and individuals, to trace change over time, and to explain the motivational bases of attitudes and behavior. Application of the values in the social sciences in the 20th century has led to the conception of basic values, of the content and structure of relations among these values, and of reliable empirical methods to measure them, which is not agreed upon vehemently by all scholars (Hitlin \& Piliavin, 2004; Rohan, 2000). Recent theoretical and methodological developments (Schwartz, 1992; Smith \& Schwartz, 1997) have brought about a resurgence of research on values especially in relation with language learning.

The value theory deals with the basic values that people in all cultures recognize. It showcases ten motivationally distinct types of values and identifies the dynamic relations among them. Some values are in conflict with one another (e.g., benevolence and power) whereas others are compatible with one another (e.g., conformity and security). The "structure" of values refers to these relations of conflict and congruence among values. Values are structured in similar ways across culturally diverse groups. This suggests that there is a universal organization of human motivations (Schwartz, 1992, 2006a, 2012). Although the nature of values and their structure may be universal, individuals and groups differ substantially in the relative importance they attribute to the values. That is, individuals and groups have different value "priorities" or "hierarchies."

The value theory (Schwartz, 1992, 2006a, 2012) adopts a conception of values that specifies six main features that are implicit in the writings of many theorists:

(1) Values are beliefs linked inextricably to affect. When values are activated, they become infused with feeling. People for whom independence is an important value become aroused 
if their independence is threatened, despair when they are helpless to protect it, and are happy when they can enjoy it.

(2) Values are concerned with desirable goals that motivate action. People for whom social order, justice, and helpfulness are important are motivated to pursue these goals.

(3) Values transcend specific actions and situations. Obedience and honesty values, for example, may be relevant in the workplace or school, in business or politics, with friends or strangers. This feature distinguishes values from norms and attitudes that usually refer to specific actions, objects, or situations.

(4) Values serve as standards or criteria. Values guide the selection or evaluation of actions, policies, people, and events. People decide what is good or bad, justified or illegitimate, worth doing or avoiding, based on possible consequences for their cherished values. But the impact of values in everyday decisions is rarely conscious. People act without thinking twice but deep down they are deeply embroiled in values they cherish.

(5) Values have an implicit hierarchy. People's values form an ordered system of priorities that characterize them as individuals.

(6) The relative importance of multiple values guides action. Any attitude or behavior typically has implications for more than one value. For example, attending classes punctually might express and promote achievement and conformity values at the expense of hedonism and benevolence values. The tradeoff among relevant, competing values guides attitudes and behaviors (Schwartz, 1992, 1996). Values influence action when they are relevant in the context (hence likely to be activated) and important to people.

\section{Benevolence}

Benevolence is about preserving and enhancing the welfare of those with whom one is in frequent personal contact (the 'in-group'). It derives from the basic requirement for smooth group functioning (Kluckhohn, 1951) and from the organismic need for affiliation (Maslow, 1965). Benevolence focuses on voluntary concern for others' welfare. Such people are helpful, honest, forgiving, responsible, loyal, and affectionate. Benevolent people have a great sense of belonging with strong faith in spiritual life. Benevolence and conformity both promote cooperative and supportive social relations. The fine difference is that benevolence provides an internalized motivational base for such behavior and in contrast, conformity promotes cooperation in order to avoid negative outcomes for self. Both values may motivate the same helpful act, separately or together.

\section{Universalism}

Universalism refers to understanding, appreciation, tolerance, and protection for the welfare of all people and for nature. This contrasts with the in-group focus of benevolence values. Universalism is rooted in survival needs of individuals and groups. However, people do not recognize these survival needs until they encounter others beyond the extended primary group and until they become aware of the scarcity of natural resources. People may then realize that failure to accept 
others who are different and treat them justly will lead to life-threatening strife. They may also realize that failure to protect the natural environment will lead to the destruction of the resources on which life depends. Universalism combines two subtypes of concern-for the welfare of those in the larger society and world and for natüre. People holding this value are broadminded and care for social justice, equality, world at peace, world of beauty, unity with nature, wisdom, and the environment.

\section{Self-Direction}

Self-direction concerns independent thought and action--choosing, creating, exploring. Selfdirection derives from organismic needs for control and mastery (Bandura, 1977; Deci, 1975) and interactional requirements of autonomy and independence (Kluckhohn, 1951; Kohn \& Schooler, 1983). People with a high sense of self-direction are creative, curious, and independent.

\section{Stimulation}

Stimulation deals with excitement, novelty, and challenge in life. Stimulation derives from the organismic need for variety and stimulation in order to maintain an optimal, positive, rather than threatening, level of activation (Berlyne, 1960). People who are stimulated look for a varied life full of excitement.

\section{Hedonism}

Hedonism encompasses pleasure or sensuous gratification for oneself. Hedonism is rooted in organismic needs and the pleasure associated with satisfying them. Hedonists try to achive the ultimate sense of pleasure, enjoyment of life and they are self-indulgent.

\section{Achievement}

Achievement encapsulates personal success through demonstrating competence according to standard criteria. Achievement is necessary for individuals to survive and for groups and institutions to reach their objectives. Ambitious people try to seek for power, enjoy demonstrating competence, thereby obtaining social approval. Such peopleare very ambitious, successful, capable, and influential.

\section{Power}

Power is about social status and prestige, control or dominance over people and resources. The functioning of social institutions apparently requires some degree of status differentiation, namely power (Parsons, 1951). Power relations emerge in analyses of interpersonal relations both within and across cultures (Lonner, 1980). Both power and achievement values focus on social esteem. However, achievement (ambition) emphasizes the active demonstration of successful performance in concrete interaction, whereas power (authority, wealth) stresses the attainment or preservation of a dominant position within the more general social system. 


\section{Security}

Security refers to safety, harmony, and stability of society, of relationships, and of self. Some security values are about individual interests and others address wider group interests such as national security. People cherishing security believe in social order, family security, and national security.

\section{Conformity}

Conformity deals with restraint of actions, inclinations, and impulses likely to upset or harm others and violate social expectations or norms. Conformity derives from the notion that individuals inhibit inclinations that might disrupt and undermine smooth interaction and group functioning. Conformity values emphasize self-restraint in everyday interaction, usually with close others. Conformist people are likely to be obedient, self-disciplined, polite, loyal, and dutiful.

\section{Tradition}

Tradition refers to respect, commitment, and acceptance of the customs and ideas. Groups everywhere develop practices, symbols, ideas, and beliefs that represent their shared experience and fate. These become sanctioned as valued group customs and traditions. They symbolize the group's solidarity, express its unique worth, and contribute to its survival (Durkheim, 1912/1954; Parsons, 1951). They often take the form of religious rites, beliefs, and norms of behavior. Traditional people have high respect for rituals, conventions with a great sense of humility and acceptance.

\section{Method}

Participants are 56 students from 20 countries from Africa, Middle East and Asia studying to get bachelors's and master's degrees at a western state university. Their ages range from 18 to 28 .

\section{Instrumentation}

The Schwartz Value Survey: The first instrument developed to measure values based on the theory is now known as the Schwartz Value Survey (SVS; Schwartz, 1992, 2006a). Respondents rate the importance of each value item "as a guiding principle in MY life" on a 5-point scale labeled 5 (very important), 4 (important), 3 (undecided), 2 (not important), 1 (not very important- opposed to my values). People view most values as varying from mildly to very important. The alpha reliability is found to be, 86 for the respondents in this study. 


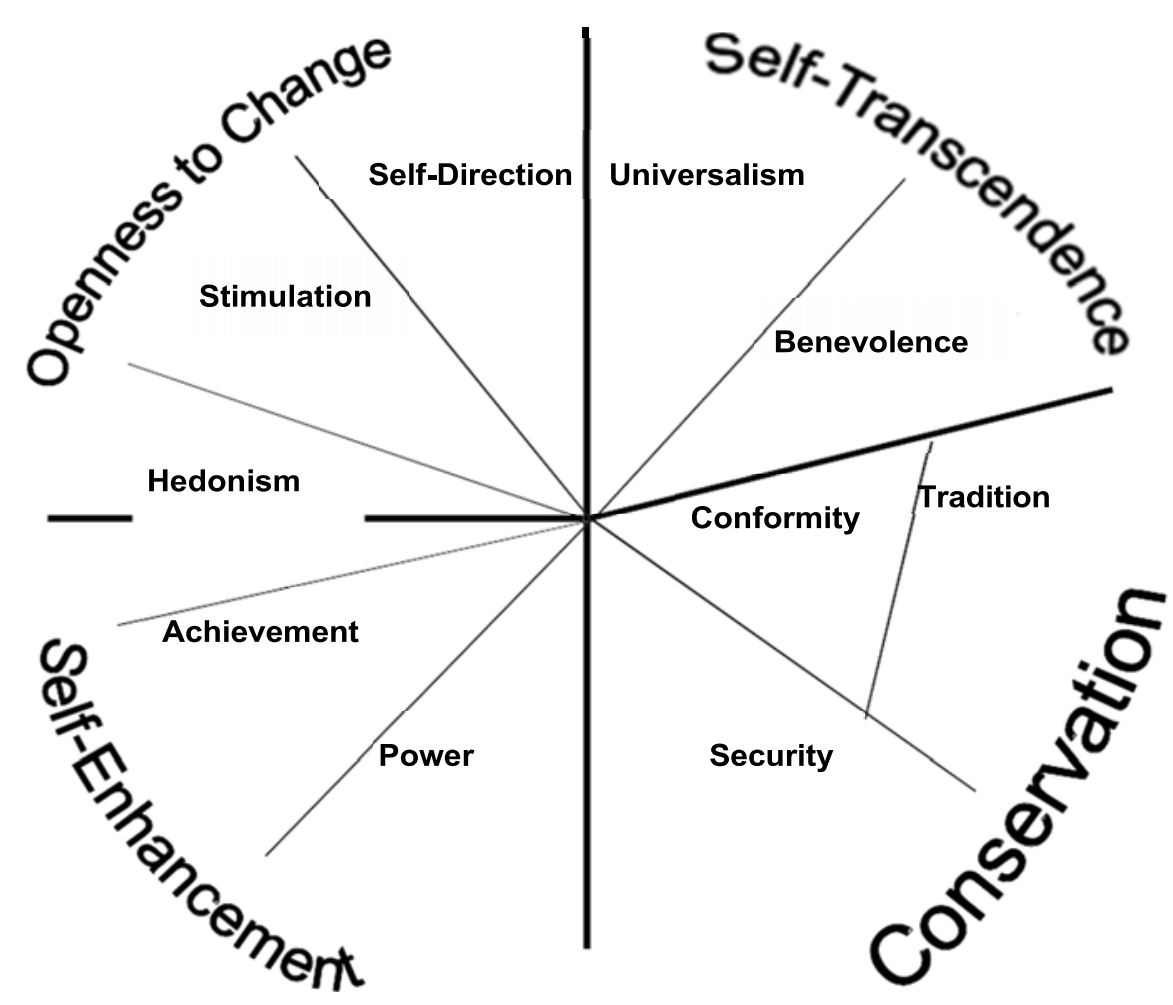

Figure 1. Theoretical model of relations among ten motivational types of value (Schwartz. 2012. p.9)

\section{Data results}

To primarily showcase whether there is a correlation between the success levels of the language learners and their motivational type of values, and secondly to explore whether this is culture specific or not, 56 language learners participated in the study and The Schwartz Values Questionnaire was administered to the students at a prep department of a state university.

Table 1

Gender descriptives

\begin{tabular}{llll} 
& $\mathrm{N}$ & Mean & Std. Deviation \\
\hline $\mathrm{M}$ & 42 & 77.9524 & 11.49327 \\
$\mathrm{~F}$ & 14 & 81.4286 & 12.40790
\end{tabular}

As Table 1 shows, there are 42 males and 14 females in the research. 
Table 2

Independent Samples Test for gender

Levene's Test for Equality of Variances

\begin{tabular}{llccccc}
\hline & & $\mathrm{F}$ & $\mathrm{Sig}$ & $\mathrm{t}$ & $\mathrm{df}$ & Sig. \\
\hline total & Equal variances assumed & .004 & .952 & -.961 & 54 & .341 \\
\hline & Equal variances not assumed & & & -.924 & 20.956 & .366
\end{tabular}

Table 2 shows there is no relation between gender and their values. Both females and males have similar ratios in terms of values.

Table 3

Values and Ages

\begin{tabular}{llcccc} 
& Sum of Squares & df & Mean Square & F & Sig. \\
\hline Between Groups & 90.161 & 3 & 30.054 & .210 & .889 \\
\hline Within Groups & 7454.054 & 52 & 143.347 & & \\
\hline Total & 7544.214 & 55 & & &
\end{tabular}

Table 3 highlights age has no bearing on the values of language learners. Although their ages vary between 18 and 28 and they are both undergraduate and graduate students at the university. this does not affect their penchant for ten values categorized by Schwartz.

Table 4

Descriptives for values

\begin{tabular}{|c|c|c|c|c|c|}
\hline & Mean & Std. Deviation & & Mean & Std. Deviation \\
\hline benevolence & 1.6786 & .57547 & Achievement & 2.0536 & .77271 \\
\hline B2 & 1.9286 & .91168 & a2 & 2.1250 & .93541 \\
\hline b3 & 1.8214 & .69038 & a3 & 2.0357 & .89370 \\
\hline b4 & 2.4643 & .85204 & $\mathrm{a} 4$ & 2.4107 & .84803 \\
\hline universalism & 1.2679 & .58748 & Power & 2.9821 & 1.13604 \\
\hline $\mathrm{u} 2$ & 1.5893 & .62601 & p2 & 2.8393 & .86921 \\
\hline $\mathrm{u} 3$ & 1.1964 & .40089 & p3 & 2.7321 & 1.05298 \\
\hline $\mathrm{u} 4$ & 1.3571 & .55362 & Security & 1.6250 & .70227 \\
\hline u5 & 1.4821 & .66033 & $\sec 2$ & 1.4286 & .70986 \\
\hline u6 & 1.6429 & .92301 & $\sec 3$ & 2.0000 & 1.17551 \\
\hline Self-direction & 1.5179 & .66033 & $\sec 4$ & 1.8393 & .88988 \\
\hline $\mathrm{sd} 2$ & 1.5714 & .70986 & Conformity & 3.0357 & 1.22050 \\
\hline $\mathrm{sd} 3$ & 1.8571 & .74903 & co2 & 2.7679 & .93402 \\
\hline sd4 & 1.5536 & .73657 & $\operatorname{co} 3$ & 2.1964 & 1.11876 \\
\hline Stimulation & 1.7500 & .81464 & $\operatorname{co} 4$ & 1.6429 & .86189 \\
\hline s2 & 2.5179 & .89425 & Tradition & 2.1607 & 1.05790 \\
\hline s3 & 1.9643 & .91382 & $\operatorname{tr} 2$ & 2.9107 & 1.26888 \\
\hline Hedonism & 1.9464 & .81842 & $\operatorname{tr} 3$ & 3.3929 & 1.17053 \\
\hline h2 & 1.3750 & .55800 & $\operatorname{tr} 4$ & 2.4464 & 1.00760 \\
\hline h3 & 1.7143 & .65267 & & & \\
\hline
\end{tabular}


The descriptives showcase that the learners are very traditional and they do not have high universal values. Their self-direction values are low. When the subtypes of values are analysed, the list is as follows: Tradition, power, conformity, stimulation, achievement, security, selfdirection, hedonism, benevolence, universalism. For Schwartz, benevolence, universalism, and self-direction values are the most important; besides, power and stimulation values are the least important, with which the respondents here disagree. The pan-cultural hierarchy provides a baseline to which to compare the priorities in any sample, however, the respondents of this study most of whom are from African and Asian countries tend to decline the priority of benevolence and universalism.

Table 5

Correlation between values and achievement

\begin{tabular}{lccc}
\multicolumn{4}{c}{ total } \\
\hline total & Pearson Correlation & 1 & at \\
\hline at & Pearson Correlation & $0.714^{* *}$ & 1 \\
$* *$ Correlation is significant at the & 0.01 level (2-tailed). & $\mathrm{N}=56$
\end{tabular}

Table 5 shows that the correlation between achievement and motivational types is high. The fact that they are all funded by The Republic of Turkey might be related to their strong drive to be successful. Compared to their countries, the amount of scholarship is quite high hereand the dormitories they live in is free of charge.

\section{Discussion and Conclusion}

Individuals show differences in the importance they attribute to these ten values. Across societies, however, there is surprising consensus regarding the hierarchical order of the values. It is contentious that across representative samples, using different instruments, the importance ranks for the ten values are quite similar. Schwartz (2012) himself believes that benevolence, universalism, and self-direction values are the most important. Power and stimulation values are the least important. However, the fact that the responses of the African and Asian students show that for them power and tradition are more important highlights the fact that these students might wish to have power when they go back to their country and they are very devoted to their own cultural values and traditions and they are not ready to embrace a liberal attitude. The pan-cultural hierarchy provides a benchmark to compare the priorities in learners. Such comparison is critical for identifying the notion that for these learners benevolence is not significantly crucial and rather than universalism, they prefer the conventional life style. This contradicts the assumption that a sample may rank benevolence highest, for example, but compared with other samples the importance rating of this value may still be relatively low.

It is socially functional to legitimize gratification of the needs and desires as long as this does not undermine group goals. Individuals must be motivated to invest time and effort to perform productive work, to solve problems that arise when working, and to generate new ideas and fruitful. Unlike the other groups who showed some congruence with Schwartz's theory, the respondents of 
this study prefer the opposite value beliefs. Despite this, they strive hard to get high scores. Their commitment to studying harder and clinging to their own interests and cultural traditions might be in conflict with the universal values all language learners are supposed to have, however, one should remember that the current trend in the world is not liberalism but conservatism.

Security and conformity values also promote harmonious social relations. These values help people to avoid conflict and violations of group norms. But these values are usually acquired in response to demands and sanctions to avoid risks, control forbidden impulses, and restrict the self. This reduces their importance because it conflicts with gratifying self-oriented needs and desires. The respondents in this study show conformity as the third priority on the list but security is the sixth, which emphasizes the fact that this is not something they care for in Turkey as it might be related to the host country's inclusive and embracing ways towards the foreigners.

To conclude it is safe to say that people everywhere experience conflict between pursuing openness to change values or conservation of values. As Schwarts (2012) believes people also experience conflict between pursuing self-transcendence or self-enhancement values. Conflicts between specific values (e.g., power vs. universalism, tradition vs. hedonism) are also nearuniversal as this study corroborates. The countries the respondents come from are war-trodden and the places they live in back in their home countries are poverty-stricken. Their aim to pursue a better life style and higher education might contribute to their being less hedonist, benevolent but more ambitious and power oriented.

\section{References}

Bandura, A. (1977). Self efficacy: Toward a unifying theory of behavioral change. Psychological Review, 84, 191215. http://dx.doi.org/10.1037/0033-295X.84.2.191.

Berlyne, D. E. (1960). Conflict, arousal and curiosity. New York: McGraw-Hill.

Bilsky, W., Janik, M., \& Schwartz, S. H. (2011). The structural organization of human values - Evidence from three rounds of the European Social Survey (ESS). Journal of Cross-Cultural Psychology, 42, 759776.http://dx.doi.org/10.1177/0022022110362757.

Brocke, B. \& Bilsky, W. (2005, July). The measurement of value preferences by paired comparisons. Paper presented at the 1st European Association for Survey Research Conference, Barcelona, Spain.

Campbell, D. T. (1975). On the conflicts between biological and social evolution and between psychology and moral tradition. American Psychologist, 30, 1103-1126. http://dx.doi.org/10.1037/0003-066X.30.12.1103.

Carter, R. (1998). Vocabulary: Applied Linguistic Perspective. London: Routledge.

Chamot, A. U. \& J. Rubin. (1994). Comments on Janie Rees-Miller's “'A critical appraisal of learner training: Theoretical bases and teaching implications', TESOL Quarterly, 28: 771-6.

Chamot, A. U., S. Barnhardt, P. B. El-Dinary,\& J. Robbins. (1999). The Learning Strategies Handbook. New York: Longman.

Cohen, A. D. (1998). Strategies in Learning and Using a Second Language. Harlow: Longman.

Cohen, A. D. (2002). Preparing teachers for styles and strategies-based instruction, in V. Crew, C. Davison, and B. Mak (eds): Reflecting on Language in Education. Hong Kong: The Hong Kong Institute of Education. 
Davidov, E., Schmidt, P., \& Schwartz, S. H. (2008). Bringing values back in: The adequacy of the European Social Survey to measure values in 20 countries. Public Opinion Quarterly, 72, 420-445. http://dx.doi.org/10.1093/poq/nfn035.

Deci, E. L. (1975). Intrinsic motivation. New York: Plenum.

Durkheim, E. (1897/1964). Suicide. Glencoe, Il.: Free Press.

Durkheim, E. (1912/1954). The elementary forms of religious life. Glencoe, IL: Free Press.

Feather, N. T. (1995). Values, valences. and choice: The influence of values on the perceived attractiveness and choice of alternatives. Journal of Personality and Social Psychology, 68, 1135-1151. http://dx.doi.org/10.1037/00223514.68.6.1135.

Freud, S. (1933). New introductory lectures in psychoanalysis. New York: Norton.

Hitlin, S. \& Piliavin, J. A. (2004). Values: Reviving a dormant concept. Annual Review of Sociology, 30, 359-393. http://dx.doi.org/annurev.soc.30.012703.110640.

Kluckhohn, C. (1951). Values and value-orientations in the theory of action: An exploration in definition and classification. In T. Parsons \& E. Shils (Eds.), Toward a general theory of action (pp. 388-433). Cambridge, MA: Harvard University Press.

Kohn, M. L., \& Schooler, C. (1983). Work and personality. Norwood, NJ: Ablex.

Leung, K., \& Bond, M. H. (2004). Social axioms: A model of social beliefs in multi-cultural perspective. In M. P. Zanna (Ed.), Advances in experimental social psychology (Vol. 36, pp. 119-197). San Diego, CA: Academic Press. http://dx.doi.org/10.1016/S0065-2601(04)36003-X.

Lonner, W. J. (1980). The search for psychological universals. In H. C. Triandis \& W. W. Lambert (Eds.), Handbook of cross-cultural psychology. Perspectives (Vol. 1, pp.143-204). Boston, MA: Allyn \& Bacon.

Maslow, A. H. (1965). Eupsychian management. Homewood, IL: Dorsey.

McClelland, D. C. (1961). The achieving society. Princeton, NJ: Van Nostrand.

Morris, C. W. (1956). Varieties of human value. Chicago, IL: University of Chicago Press.

Oishi, S., Schimmack, U., Diener, E., \& Suh, E. (1998). The measurement of values and individualism-collectivism. Personality and Social Psychology Bulletin, 24, 1177-1189. http://dx.doi.org/10.1177/01461672982411005.

O’Malley, J.M. \& A. U. Chamot.(1990). Learning Strategies in Second Language Acquisition. New York: Cambridge University Press.

O’Malley, J. M., A. U. Chamot, G. Stewner-Manzanares, R. Russo, \& L. Kupper. (1985).Learning strategy applications with students of English as a second language, TESOL Quarterly, 19: 557-84.

Oxford, R. L. (1990). Language Learning Strategies:What Every Teacher Should Know. New York: Newbury House.

Oxford, R. L. (ed.) (1996). Language Learning Strategies Around the World: Cross-Cultural Perspectives. Honolulu, HI: University of Hawaii Press.

Pintrich, Parsons, T. (1951). The social system. Glencoe, IL: Free Press.

Schwartz, S. H. (1992). Universals in the content and structure of values: Theory and empirical tests in 20 countries. In M. Zanna (Ed.), Advances in experimental social psychology (Vol. 25, pp. 1-65). New York: Academic Press.http://dx.doi.org/10.1016/S0065-2601(08)60281-6

Schwartz, S. H. (1994). Are there universal aspects in the content and structure of values? Journal of Social Issues, 50, 19-45. http://dx.doi.org/10.1111/j.1540-4560.1994.tb01196.x.

Schwartz, S. H. (1996). Value priorities and behavior: Applying a theory of integrated value systems. In C. Seligman, J. M. Olson, \& M. P. Zanna (Eds.), The psychology of values: The Ontario Symposium (Vol. 8, pp. 1-24). Hillsdale, NJ: Erlbaum. 
Schwartz, S. H. (2006a). Les valeurs de base de la personne: Théorie, mesures et applications [Basic human values: Theory, measurement, and applications]. Revue Française de Sociologie, 47, 249-288.

Schwartz, S. H. (2006b). Value orientations: Measurement, antecedents and consequences across nations. In Jowell, R., Roberts, C., Fitzgerald, R. \& Eva, G. (Eds.) Measuring attitudes cross-nationally - lessons from the European Social Survey (pp.169-203). London, UK: Sage.

Schwartz, S. H., \& Bardi, A. (1997). Influences of adaptation to communist rule on value priorities in Eastern Europe. Political Psychology, 18, 385-410. http://dx.doi.org/10.1111/0162-895X.00062.

Schwartz, S. H., \& Boehnke, K. (2004). Evaluating the structure of human values with confirmatory factor analysis. Journal of Research in Personality, 38, 230-255. http://dx.doi.org/10.1016/S0092-6566(03)00069-2.

Schwartz, S. H. (2012). An Overview of the Schwartz Theory of Basic Values. Online Readings in Psychology and Culture, 2(1),1-20. http://dx.doi.org/10.9707/2307-0919.1116

Smith, P. B., \& Schwartz, S. H. (1997). Values. In J. W. Berry, M. H. Segall \& C. Kagitcibasi (Eds.), Handbook of cross-cultural psychology, (2nd ed., Vol. 3, pp. 77-118). Boston, MA: Allyn \& Bacon.

Weber, M. (1905/1958). The Protestant ethic and the spirit of capitalism. New York: Scribner's.

Williams, R. M., Jr. (1968). Values. In E. Sills (Ed.), International encyclopedia of the social sciences (pp. 283-287). New York: Macmillan. 